in another it might be more or less than eight hours. So too within a single industry one worker might labor longer than another. Such a solution could be made to satisfy both economic and social demands and lead to the maximum of individual and national efficiency.

I quite realize the difficulties inherent in putting into practise a system which does not recognize the magic eight hours as the ideal, and especially the still greater diffculties in the establishment of a system in which within a single occupation one person works longer than another. But I believe that these difficulties would prove less formidable if we would once get accustomed to the notion that individual capacity is the first criterion to be considered in deciding upon labor's duration. The adjustment of wages according to individual capacity I will leave to the economists.

In view of all this how fatuous was the action of the state of California in voting, in 1914, on the question whether the eighthour day should be adopted! The proposition was defeated by about two to one, but the decision was necessarily a matter of sentiment, resting on no basis of adequate knowledge. ' An affair of such serious moment ought not to be decided by uninstructed popular feeling. The recent action of Congress in imposing, after a few hours' consideration, an eight-hour day upon railway employees can hardly be called more sagacious than the action of California. The Adamson bill, however, has little bearing on the general principle of the eight-hour day.

It is obvious that any formal regulation of the duration of daily labor is for those whose daily services are employed by others. By so much as a man rises above this stage he becomes free to choose his own working-time. It is a noteworthy fact that with the world's leaders, in industry, in finance, in professional life, the duration of the daily task is wholly secondary to its accomplishment. They are limited by no eight-, or ten-, or twelve- or sixteen-hour considerations. This indicates why such men become leaders. Laborers can learn a valuable lesson from this fact. The greedy employer who constantly saps the energies of those who are the medium by which he gains his wealth is to be condemned no more than is the "slacker" whose only guiding principles are a minimum of effort and a maximum of wage. Moreover, it is trite to say that the obligation rests upon the laborer that rests upon all men, so to use his free hours as to benefit himself, his family and society.

In conclusion I can not refrain from quoting, with warm approval of their sentiments and of their application to our own country, the recent significant words of Sir George Newman regarding British industries :

Our national experience in modern industry is longer than that of any other people. It has shown clearly enough that false ideas of economic gain, blind to physiological law, must lead, as they led through the nineteenth century, to vast national loss and suffering. It is certain that unless our industrial life is to be guided in the future by the application of physiological science to the details of its management, it can not hope to maintain its position hereafter among some of its foreign rivals, who already in that respect have gained a present advantage.

CoLUmbia UNIVErsitit

Frederic S. Lee

\section{THE CARE OF PAMPHLET COLLECTIONS ${ }^{1}$}

THE published articles pertaining even to the most restricted fields of science are scattered through a very large number of serial publications of which only the larger institutions of learning and research are able to possess complete sets. The high cost and large bulk of such series preclude their being owned

1 Contribution from the Museum of Vertebrate Zoology of the University of California. 
by individual investigators or by the smaller institutions, and the general result is that the worker who desires to cover the literature of his particular field must have access to a collection of reprints and excerpts of such articles, gathered either independently, or by the institution with which he is connected. Thus most investigators have occasion to assemble and care for a pamphlet collection. The present paper considers some of the expedients commonly employed for this purpose and calls attention to a particular scheme which has been found satisfactory in the care of one collection.

Before a pamphlet collection can be effciently used it must be properly arranged. The time thus spent will bring ample return in the added facility with which particular papers can be located when they are desired. In addition to this the exercise of a few simple precautions will do much to prolong the life and increase the usefulness of the pamphlets in a library. Dust, strong light and careless handling all help to depreciate the value of pamphlets. As time goes on and by one means or another, the copies of certain papers decrease in number; those which remain inevitably increase in value and become more diffcult to obtain. It is needless to insist on the advisability of arresting these losses.

The methods in use for assorting and conserving pamphlets are various. Some collections are arranged to satisfy special needs, while others have no further purpose in their organization than that of general convenience. A popular method is to keep the reprints in flat piles on shelves. This, however, does not permit ready location, and removal of single papers from the pile involves a risk of tearing either them or the sheets adjacent to them. A second device is to place the pamphlets vertically on a shelf. This makes it possible to remove any desired paper without disturbing those adjacent to it. But unless there are frequent vertical partitions for support, the pressure exerted by the weight of the papers on either side makes the removal of thin pamphlets difficult. Both of these methods expose the collection to light and dust. A third method is to bind the pamphlets in volumes. This obviates the danger of damage by light or dust, but is still open to several serious objections. Chief among these is the difficulty of arranging the papers in a thoroughly convenient manner for ready reference. Of course where there are a number of papers by a single author these may be readily bound together chronologically in one or more volumes, but where the assortment is varied the problem of assembling for binding is more complex. All of the papers of one author may not be on hand when the binding is done; the contents of bound volumes can not be so readily indexed as can separate papers; and the papers contained therein can not be so easily laid out for study as when separate and unbound. A final objection to binding is that it involves considerably more expense than most of the other modes of filing.

A fourth method is to place the pamphlets in vertical filing cabinets. This economizes space as regards depth more than any of the other systems here mentioned but the cost of the containers is quite high-ranking close to or above that of binding the papers in volumes, according as the cabinet selected is of the rough "transfer" or highly finished type.

The last plan we shall notice is one that is probably in more general use than any other, namely, placing the pamphlets in narrow pamphlet cases. These are of three general types. The first resembles a small letter file with a hinged back which completely protects the contents from dust and light. This case is heavier and much more expensive than the others and is slightly more inconvenient to handle because of the necessity of opening the back when removing the contents. The second type has both top and back open and while it will accommodate pamphlets of widely different sizes it exposes portions of the papers to the harmful action of dust and light. The third type, a box open only at the back, seems by far the most convenient, as when pushed against a wall it is practically dust and light proof, though still permitting ready reference to its contents. Cases 12 inches high, 8 inches deep and $2 \frac{1}{2}$ inches wide, made of a 
good weight of strawboard faced on the inside with white paper and entirely covered on the outside with black binder's cloth, have been found to give excellent results. These seem even more durable than cases with wooden tops and bottoms, as they have a slight "give" which seems to make them more lasting. A set of cases of this sort has been in constant use at the Museum of Vertebrate Zoology of the University of California for more than six years without showing appreciable wear. The size suggested will take all octavo publications and even the smaller quartos, and when completely filled the weight is still not too great for easy handling. Cases measuring more than $2 \frac{1}{2}$ inches in width are not satisfactory; they soon break to pieces under pressure of the greater weight of the material they hold. They often, moreover, hold too many papers for quick reference, while the narrower boxes permit of a finer classification. With the smaller size additional boxes may be interpolated as necessity arises, before a complete revision of the collection is required.

Three methods of filing the pamphlets of a collection are in general use; filing by subject, by author's surname, and by date of accession. For a small collection with which the worker is well acquainted and where there are few if any papers of such a nature as not to fall readily into one class or another, or in very large collections comprising papers on such distinct subjects as geography, geology and zoology, the subject classification is possibly the most convenient. But in large collections devoted to a narrower field the alphabetical segregation by authors is much more satisfactory. With papers so arranged and those of single authors in chronological order, no author index is needed. A third system, used somewhat more rarely, is to file pamphlets in the order of their receipt, giving them serial numbers, and maintaining both author and subject indexes for reference purposes. Such an arrangement has the advantage of not being disturbed by later accessions, these being added at the end of the collection. Under this system, however, the papers must be kept absolutely in order if they are to be found at all.
If cases are used to shelter the collection, some kind of case inscription is necessary, whatever system is adopted. When the clothcovered cases described above are used, pieces of white paper, about $1 \frac{3}{4}$ inchès square, are pasted on the fronts of the boxes near their tops. On these labels are placed inscriptions designating the case contents. If the subject arangement is used, the title is made comprehensive enough to include all papers which are or may be filed in that case. If the author classification is used, a large initial letter is placed at the top and below it abbreviations indicating the names of the authors whose papers are filed in that case. Thus, for the case containing papers from Brown to Burns the inscription would be

$$
\begin{gathered}
\mathrm{B} \\
\mathrm{Br}-\mathrm{Bu} .
\end{gathered}
$$

If one author's papers are sufficiently numerous to require one or more complete cases their fronts bear his initial and name and an indication of the years covered by the papers included, thus:

\section{0}

Oberholser, H. C. 1905-1914

\section{0}

Oberholser, H. C. 1914
When first arranging or when revising the arrangement of a pamphlet collection, sufficient room should be left in individual cases to anticipate considerable expansion-no case should be more than two thirds filled at first, save for a single author, unless the collection is already large and the expense of additional cases is an object for consideration. Thus a large number of papers can be added to the collection before it need be completely revised and relabelled.

Whatever method of arrangement is adopted some sort of finding index is necessary to make all the papers readily accessible. If any.system other than that of filing by authors' names is adopted a catalogue of authors is needed. If the subject classification is adopted a card should be used for each author, the entries being made as follows:

Ridgway, $R$.

1892. Hummingbirds (Aves: systematic)

1897. Galapagos Is. birds (Faunal: S. Amer.) 
The words in parentheses indicate where the paper is filed. When papers are filed by the accession method the same sort of entries are made in the author catalogue save that the serial number of the paper is included in the parentheses at the right. Thus:

Ridgway, $\mathbf{R}$.

1892. Hummingbirds (642)

1897. Galapagos Island birds (1489)

Where papers are arranged by authors a subject index only is needed. For example, in the writer's own index for papers in vertebrate zoology there are included cards for systematic, and for geographic or faunal entries. Many papers require entry under both headings and some under even more. Thus, a paper by Ruthven, Thompson and Thompson, entitled "The Herpetology of Michigan," would be entered under "Reptiles," "Amphibians" and "Michigan." In this way the paper can be found under any of the three titles carded. The form of subject index entries is indicated by the following samples:

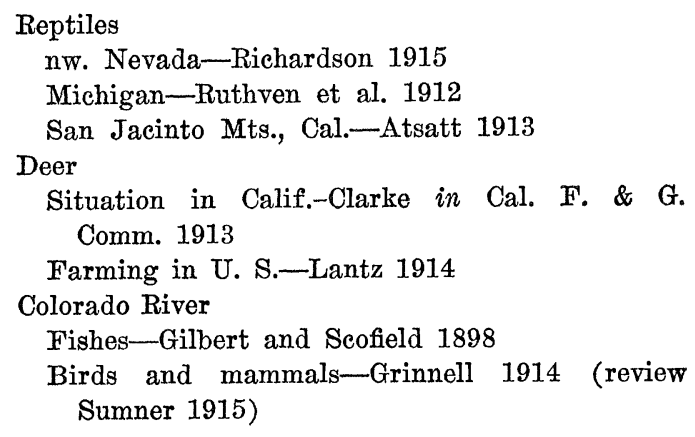

Papers often occur which are difficult of exact classification and it is well to have general headings under which these may be included, as for example "Birds," "Mammals," "Variation," etc. These titles may be subdivided, as the papers accumulate.

For all indexes the standard sized 3 by 5 inch cards of librarians and bibliographers are the most suitable. In entering the references a carbon ink such as Higgins Eternal is recommended because of its permanency of color and the uniformity of entries made at different times.

As a result of the great variation in the manner of placing the title, author's name and date of publication on the covers of reprints or pamphlets considerable time is lost in searching for these items when looking through a file. An easy way of overcoming this difficulty is to annotate the upper lefthand corner of the front of each paper with the author's name and initials, the date, and a catch title, in the form used by Professor E. L. Mark, of Harvard, thus:

$$
\begin{array}{cc}
\text { Ruthven, A. G., et al. } & \text { Rutter, C. } \\
: 12 & : 08 \\
\text { Herpetology of } & \text { Sacto.-San Joaquin } \\
\text { Michigan } & \text { Valley } \\
& \text { Fishes } \\
& \text { Ridgway, R. } \\
& : 92 \\
\text { Hummingbirds }
\end{array}
$$

The catch titles are arranged so that in looking down the left-hand margin the eye encounters the most important words first. With pamphlets so marked only a few seconds are required to secure any particular paper and it is often possible to locate it without removing the others from the case. Where there are a number of papers by a single author it is well to number them serially beginning with the oldest one. Then when a paper is withdrawn it can be quickly and correctly replaced by its number without having recourse to the date. For these annotations, as with catalogue cards, carbon ink should be used. Another method which has been used for the same purpose as these corner annotations is to underscore the author's name, the date and the title.

Serial publications are best kept in sets by themselves as they are received, but where the individual articles comprising a volume are issued in separate form these may be run into the general collection along with other pamphlets. Later on they can, if desired, be removed and bound in complete volumes. The writer has a considerable number of pamphlets relating to subjects outside his main line of work but which for one reason or another he desires to keep. These are arranged according to the names of their authors, and kept in a "reserve" file, where they can be 
easily located. Many of them are complementary parts of complete volumes, the other papers of which are in his main pamphlet collection.

The date of receipt should always be written on the pamphlet as soon as it comes to hand. With some series no date of publication is given on the separate papers, and as they may have been issued in advance of the appearance of the complete volume, it often becomes important to know their dates of receipt, as in the case of papers describing new species of animals or plants.

In summary, then, the writer would recommend that a pamphlet collection be placed in cloth-covered cardboard cases open only at the back and not larger than $12 \times 8 \times 2 \frac{1}{2}$ inches, that it be arranged alphabetically by authors' names and chronologically under authors, that the corner of each pamphlet be annotated with the author's name, the date, and a catch title, and that a subject index be maintained to facilitate the location of particular pamphlets. A collection so arranged and housed renders the greatest amount of service, and is reasonably insured against deterioration.

\section{Berkeley, California}

Tracy I. STORER

\section{THE BRAIN COLLECTION OF THE U. S. NATIONAL MUSEUM}

THE division of physical anthropology of the United States National Museum has been recently enriched by a most valuable accession of brains of some of the higher anthropoids. The accession consists of no less than eleven well-preserved brains of gorillas, and three chimpanzees. With the exception of two of the specimens belonging to young animals, the brains are in excellent condition for study. No less than six of the fourteen brains are those of adults, while most of the remaining, though not quite adult, are full-grown or nearly so.

A justifiable allusion may perhaps be made in this place to the rest of the collection of primate brains now in the division of physical anthropology, U. S. N. M.
The total collection, which was started by the writer thirteen years ago, counts now approximately 1,500 human and animal brains. Of these 223 are human, including 128 of other races than whites; while 348 belong to other primates. The latter are distributed as follows:

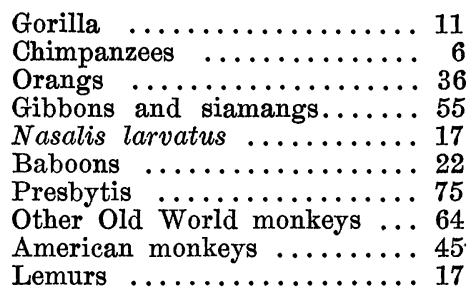

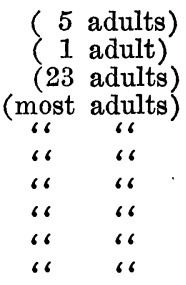

A large proportion of the above valuable material has been collected directly in or for the institution, and is in a very good condition for study. The number of adult anthropoid brains, excepting those of the chimpanzees, exceeds probably that of all other known collections of similar material not only singly, but even collectively.

Besides those of the primates, there are now in the collection the brains of 165 carnivora and cetacea; 50 insectivora; 266 ungulata; 81 rodentia; 47 edentata and marsupialia; and 287 aves and reptilia.

The whole collection, in common with others in the division and in the U. S. National Museum in general, is freely accessible for consultation to well-qualified scientific workers; and in suitable cases facilities could be extended for full elaboration and description of some of the series of specimens.

\section{ALEŠ HRDLIČKa}

\section{PROGRAM OF THE YALE CHAFTER OF SIGMA XI FOR I9I6-IgI7}

THe meetings of the Yale Chapter of Sigma $\mathrm{Xi}$ for the present college year promise to be of unusual interest, for there are to be presented, instead of the usual mutually irrelevant papers, a series of lectures which together will constitute a symposium on the origin and evolution of the earth and its inhabitants. Each paper will be authoritative, the result of original research, and the series 